\title{
Personalized therapy algorithms for type 2 diabetes: a phenotype-based approach
}

This article was published in the following Dove Press journal:

Pharmacogenomics and Personalized Medicine

19 June 2014

Number of times this article has been viewed

\section{Antonio Ceriello 1,2 \\ Marco Gallo 3 \\ Riccardo Candido ${ }^{4}$ \\ Alberto De Micheli ${ }^{5}$ \\ Katherine Esposito ${ }^{6}$ \\ Sandro Gentile ${ }^{6}$ \\ Gerardo Medea ${ }^{7}$}

'Department of Endocrinology, Hospital Clinic de Barcelona, Institut d'Investigacions Biomèdiques August $\mathrm{Pi}$ iSunyer, ${ }^{2} \mathrm{Centro}$ de Investigacion Biomèdica en Red de Diabetes y Enfermedades Metabolicas Asociadas, Barcelona, Spain; ${ }^{3}$ Oncological Endocrinology, AOU Città della Salute e della Scienza-Molinette, Turin, ${ }^{4}$ Diabetes Center, ASS I Triestina, Trieste, ${ }^{5}$ Ligurian Health Agency, Genoa, ${ }^{6}$ Department of Clinical and Experimental Medicine, Second University of Naples, Naples, ${ }^{7}$ Italian College of General Practitioners, Florence, Italy

Video abstract

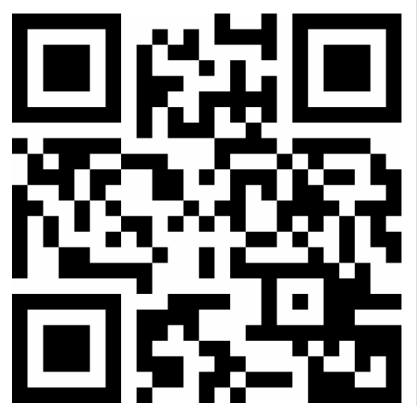

Point your SmartPhone at the code above. If you have a $Q R$ code reader the video abstract will appear. Or use: http://dvpr.es//onVmqB

Correspondence: Antonio Ceriello Institut d'Investigacions Biomèdiques August Pi iSunyer, C/Rosselló I49-I53, 08036 Barcelona, Spain Email aceriell@clinic.ub.es
Abstract: Type 2 diabetes is a progressive disease with a complex and multifactorial pathophysiology. Patients with type 2 diabetes show a variety of clinical features, including different "phenotypes" of hyperglycemia (eg, fasting/preprandial or postprandial). Thus, the best treatment choice is sometimes difficult to make, and treatment initiation or optimization is postponed. This situation may explain why, despite the existing complex therapeutic armamentarium and guidelines for the treatment of type 2 diabetes, a significant proportion of patients do not have good metabolic control and at risk of developing the late complications of diabetes. The Italian Association of Medical Diabetologists has developed an innovative personalized algorithm for the treatment of type 2 diabetes, which is available online. According to the main features shown by the patient, six algorithms are proposed, according to glycated hemoglobin $\left(\mathrm{HbA}_{1 \mathrm{c}}\right.$, $\geq 9 \%$ or $\leq 9 \%$ ), body mass index ( $\leq 30 \mathrm{~kg} / \mathrm{m}^{2}$ or $\left.\geq 30 \mathrm{~kg} / \mathrm{m}^{2}\right)$, occupational risk potentially related to hypoglycemia, chronic renal failure, and frail elderly status. Through self-monitoring of blood glucose, patients are phenotyped according to the occurrence of fasting/preprandial or postprandial hyperglycemia. In each of these six algorithms, the gradual choice of treatment is related to the identified phenotype. With one exception, these algorithms contain a stepwise approach for patients with type 2 diabetes who are metformin-intolerant. The glycemic targets $\left(\mathrm{HbA}_{1 \mathrm{c}}\right.$, fasting/preprandial and postprandial glycemia) are also personalized. This accessible and easy to use algorithm may help physicians to choose a personalized treatment plan for each patient and to optimize it in a timely manner, thereby lessening clinical inertia.

Keywords: type 2 diabetes, treatment guidelines, personalized treatment, Italian Association of Medical Diabetologists, Italian algorithm

\section{Need for a personalized treatment algorithm for type 2 diabetes}

There has been an alarming increase in the number of patients with type 2 diabetes (T2D) in recent years, mainly due to the increased prevalence of the disease in adults aged 20-79 years. The International Diabetes Federation predicts that there will be 552 million people with T2D by 2030 if urgent action is not taken. ${ }^{1}$

T2D is a progressive disease with a complex and multifactorial pathophysiology, and should be assessed and addressed in each individual with T2D. ${ }^{2,3}$ Control of glucose and other risk factors, including dyslipidemia and hypertension, should be achieved as soon as possible in order to avoid the late complications of diabetes and to maintain metabolic control benefits with time, ie, the known "legacy effect". ${ }^{4,5}$ In addition to insulin, nowadays we have a complex armamentarium of both oral and injectable antidiabetic agents. ${ }^{6,7}$ 
Each therapeutic drug class addresses different pathogenic mechanisms of T2D. Further, within each class, there are pharmacological compounds with peculiarities in terms of their pharmacodynamic and pharmacokinetic actions, resulting in some advantages and/or disadvantages, limitations, and adverse effects. In addition, there are new drugs in various stages of development within the existing pharmacological classes used to treat T2D, and other therapeutic classes are emerging. Today, seven therapeutic classes of antidiabetic agents are available, ie, biguanides (metformin only), insulin secretagogues (sulfonylureas and glinides), $\alpha$-glucosidase inhibitors, thiazolidinediones, incretin-based drugs (dipeptidyl peptidase 4 inhibitors and glucagon-like peptide 1 receptor agonists), sodium-glucose cotransporter 2 inhibitors, and insulin.

The international and national guidelines for the treatment of T2D establish a target glycated hemoglobin $\left(\mathrm{HbA}_{1 \mathrm{c}}\right)$ value (eg, $<7 \%$ ) as in the 2012 position statement of the American Diabetes Association and the European Association for the Study of Diabetes, ${ }^{8}$ which should be individualized. These guidelines recommend lifestyle modification and, if not contraindicated, metformin either from the very beginning or if the patient has failed to reach their target $\mathrm{HbA}_{1 \mathrm{c}}$ with lifestyle intervention. Even if metabolic control is initially achieved, it is likely deteriorate over time because T2D is a progressive disease, and there will be a need for intensification of treatment. ${ }^{2,9}$ Accordingly, after failure of metformin monotherapy, the current guidelines recommend addition of a second and then a third drug (oral or injectable), to be chosen from the other classes, taking into account the complementary mechanism of action, efficacy, durability, glycemic effects (action is predominantly on fasting plasma glucose or postprandial glucose), extraglycemic effects, safety (not limited just to hypoglycemia and weight gain),${ }^{10}$ simplicity, and costs. ${ }^{11}$ Only these considerations make combinations of agents possible, which are considerably more if we include all the therapeutic options that exist in each class (eg, insulin or incretin-based therapy, such as dipeptidyl peptidase 4 inhibitors or glucagon-like peptide 1 receptor agonists). Choosing between antidiabetic drug combinations becomes even more difficult to make when individual variables are taken into account, such as patient age, duration of diabetes, presence of microvascular and macrovascular diabetic complications, existence of comorbidities like cardiovascular disease or renal failure, the risk of hypoglycemia, cognitive and socioeconomic status of the patient, patient preferences, compliance, and life expectancy. The "glycemic pattern", which defines the "phenotype" of the patient, is also important for achieving predetermined glycemic targets. Indeed, according to Monnier et al, ${ }^{12}$ the contribution of postmeal and fasting glucose is approximately equal at an $\mathrm{HbA}_{1 \mathrm{c}}$ of $7.5 \%$; however, at $\mathrm{HbA}_{1 \mathrm{c}}$ levels $\leq 7.5 \%$ the contribution of postprandial glucose increases progressively with decreasing $\mathrm{HbA}_{1 \mathrm{c}}$ levels and conversely, at levels of $\mathrm{HbA}_{1 \mathrm{c}} \geq 7.5 \%$, the contribution of fasting plasma glucose predominates.

It is noteworthy that not all the possible drug combination choices are supported by meta-analysis of randomized controlled trials or even by randomized controlled trials themselves, as acknowledged by the 2012 position statement of the American Diabetes Association and the European Association for the Study of Diabetes. ${ }^{8}$ Therefore, we agree with the position statement that "many clinicians are therefore perplexed as to the optimal strategies for their patients". ${ }^{8}$

T2D is treated not only by diabetologists and endocrinologists, but also by other specialists and general practitioners, and the current guidelines include these physicians as their target audience. ${ }^{13}$ Given the situation described above, the longstanding need for implementation of clinical practice guidelines as evidence-based algorithms is not surprising. ${ }^{14}$ However, what is surprising is that, despite the existing comprehensive armamentarium and guidelines for the treatment of T2D, a significant proportion of patients do not have good metabolic control. ${ }^{15}$ The existing guidelines:

- outline the available therapeutic options for T2D, along with their mechanism of action, advantages, and disadvantages/side effects, as well as their possible combinations, presenting practitioners with multiple choices to make

- set a "general" $\mathrm{HbA}_{1 \mathrm{c}}$ target, even if some acknowledge that this target should be individualized

- with some exceptions, indicate that the $\mathrm{HbA}_{1 \mathrm{c}}$ level at entry does not influence treatment choices

- recommend lifestyle modification and metformin as initial steps; after metformin failure, not all possible combinations of recommended drugs are evidence-based

- put cost as a priority in selection of medication, prioritizing sulfonylureas as a second-line therapy

- recommend initiation of insulin using a basal or premixed insulin, and seldom with a meal-time rapid-acting insulin

- do not recommend routine self-monitoring of blood glucose for T2D not treated with insulin

- suggest that need for treatment intensification be evaluated every 3-6 months. ${ }^{8,10,11,16-19}$

Over time, the guidelines have been updated due to advances in the treatment of T2D, in response to criticism, ${ }^{20,21}$ or to meet the need for a more practical, personalized 
approach. Other national guidelines/algorithms have been born of the same need. Relevant examples include the Finnish Current Care Guideline for Diabetes ${ }^{17,18}$ and the algorithm released by the Italian Association of Medical Diabetologists (AMD) in the European Union, ${ }^{22}$ and the computer-assisted decision support tool now available in the USA. ${ }^{23}$

\section{Interactive therapeutic algorithm proposed by the AMD}

The UK Prospective Diabetes Study ${ }^{4}$ clearly showed a benefit of intensive glycemic control with regard to the microvascular complications of diabetes, but its results were inconclusive for macrovascular complications. Further, the more recent ACCORD (Action to Control Cardiovascular Risk in Diabetes), ${ }^{24}$ ADVANCE (Action in Diabetes and Vascular disease: PreterAx and DiamicroN Controlled Evaluation), ${ }^{25}$ and VADT (Veterans Affairs Diabetes Trial) ${ }^{26}$ studies reported unfavorable results from intensive glycemic control. The ACCORD trial was terminated prematurely due to a higher overall mortality in the intensively treated group versus the conventionally treated group, and ADVANCE and VADT showed that intensive control of glycemia had no significant benefit in decreasing the risk of an adverse cardiovascular outcome.

Recognizing that patients with T2D in the UK Prospective Diabetes Study were newly diagnosed, without diabetes related-complications, and younger at enrolment in comparison with those included in ACCORD, ADVANCE, and VADT, who had a long history of disease and established macrovascular complications at enrolment, the medical community proposed individualized $\mathrm{HbA}_{1 \mathrm{c}}$ targets and treatment for patients with T2D.

Young or relatively young patients with recent onset of T2D and minimal or no microvascular or macrovascular complications will benefit the most from tight glycemic control, keeping blood glucose levels as close to normal as possible. On the other hand, older patients with a longer history of diabetes and late complications of diabetes, in particular cardiovascular disease, will have higher targets that are individualized to each particular set of circumstances. These individualized targets may be adapted in response to changes in the health status or life of the individual. ${ }^{27,28}$ Eldor and Raz proposed a target $\mathrm{HbA}_{1 \mathrm{c}}<6.5 \%$ for "low risk/high benefit" patients, $<7 \%$ for "intermediate risk/ intermediate benefit" patients, and 7.5\%-8\% for "high risk/low benefit" patients. ${ }^{29}$

\section{Finnish guideline}

The current guideline for care of T2D in Finland is an algorithm available online and can be easily updated.
Each T2D patient may best fit into one of the six available "main features", ie, early diabetes, chronic diabetes with a history of more than 10 years, morbid obesity, elderly, employed in transport industry, and impaired kidney function. It also contains hyperlinks to each drug class database with concise "strengths and opportunities" on the one hand and "weaknesses and threats" on the other. Based on the risk to benefit assessment, this algorithm indicates the choice of treatment, ie, good, not as a first choice or contraindicated, and careful follow-up. ${ }^{17,18}$ Important conditions related to the patient are also taken into consideration.

\section{Computer-assisted decision support tool}

This program was first presented in $2005^{30}$ and updated twice since. ${ }^{23,31}$ As suggested by its name, the computer-assisted decision support tool can be used by general practitioners for decision making and has been implemented in some centers in the USA. The most recent version considers 69 regimens with combinations of up to four antidiabetic drugs. Patients can enter their self-monitored blood glucose values into the system and the software analyzes and interprets these data according to glycemic targets. The tool also generates a treatment recommendation that can be accepted or not by the general practitioner. Its authors stress that the clinical judgment and experience of the physician should prevail because the program (like any other) may generate errors. The program will be updated in the future to accommodate certain special populations, eg, the elderly and women with gestational diabetes.

\section{AMD algorithm Introduction}

Based on previous publications that have attempted to individualize the treatment of T2 $\mathrm{D}^{32-34}$ and the above-mentioned Finnish guideline for T2D, in 2011 the AMD released a web-based algorithm available in both Italian and English. ${ }^{22}$ The initial version was published in a peer-reviewed journal in 2012, to which the reader is referred for details regarding the algorithm. ${ }^{35}$ Since then, the AMD algorithm has been reviewed and updated twice. The last update in May 2013 was done in consultation with the Italian College of General Practitioners and was undertaken in response to the needs and concepts published on T2D treatment ${ }^{8,36}$ and to include newly approved drugs or expanded indications for existing ones in the European Union. ${ }^{37} \mathrm{New}$ targets for postprandial glucose have been included according to the guidelines published by the International Diabetes Federation, ${ }^{36}$ a new class of agents 
for the treatment of T2D (sodium-glucose cotransporter 2 inhibitors) has been introduced, and the indications for and dosing of dipeptidyl peptidase 4 inhibitors in patients with chronic renal impairment have been updated. ${ }^{37}$

A new table (Table 1) has been added describing the hypoglycemic effects on fasting plasma glucose, postprandial glucose, side effects, and costs of all approved therapeutic classes of glucose-lowering agents in the European Union by the time of revision and update of the algorithms. ${ }^{37}$ In this third version, a separate table (Table 2) is proposed for incretins and sodium-glucose cotransporter 2 inhibitors, with recommended combinations including these agents. ${ }^{37}$ Further, two new subcategories of T2D patients are included, ie, those who are metformin-intolerant (Figure 2 algorithms B-F) and elderly frail patients (Figure 2 algorithm F).

\section{Glycemic targets: $\mathrm{HbA}_{I c}$ and glycemia}

In order to minimize the risk of hypoglycemia, the $\mathrm{HbA}_{1 \mathrm{c}}$ target has been individualized based on the age of the patient (young adult $\leq 45$ years, adult $\geq 45$ and $\leq 70$ years, and elderly $\geq 70$ years) and on the presence of macrovascular complications of diabetes and comorbidities.

A more stringent $\mathrm{HbA}_{1 \mathrm{c}}$ target of $<6.5 \%$ is set for young adults with or without these complications and/or comorbidities; however, elderly individuals ( $\geq 70$ years) with macrovascular complications and/or comorbidities have an $\mathrm{HbA}_{1 \mathrm{c}}$ target of $7 \%-8 \%$ (Figure 1 ). In this age group, biological age, frailty, and glomerular filtration rate have to be carefully evaluated at the start of treatment, and thereafter periodically, according to the judgment of the clinician. For an $\mathrm{HbA}_{1 \mathrm{c}}$ target $\leq 7 \%$, glycemic values are fixed at $70-115 \mathrm{mg} / \mathrm{dL}(3.9-6.4 \mathrm{mmol} / \mathrm{L})$ for fasting/preprandial blood glucose and at $\leq 160 \mathrm{mg} / \mathrm{dL}(8.9 \mathrm{mmol} / \mathrm{L})$ for postprandial blood glucose. For an $\mathrm{HbA}_{1 \mathrm{c}}$ target $>7 \%$, both fasting/preprandial and postprandial glycemic targets are set by the clinician, taking into account the individual characteristics of the patient in order to avoid hypoglycemia.

\section{Patient phenotype}

Self-monitoring of blood glucose in noninsulin-treated patients has been shown to improve reduction of $\mathrm{HbA}_{1 \mathrm{c}}$ significantly in patients with poorly controlled T2D. ${ }^{38}$ In the AMD algorithm, patients are phenotyped on the basis of type and prevalence of blood glucose levels during the day using fasting/preprandial glucose levels and levels measured 2 hours after main meals by self-monitoring of blood glucose. The schemes proposed for self-monitoring are based on the International Diabetes Federation guideline for self-monitoring of blood glucose in noninsulin-treated type 2 diabetes. ${ }^{39}$ Consequently, three types of automonitoring schemes are proposed:

Table I All approved classes of glucose lowering agents in the European Union by the time of review and update of the algorithms (April 20I3) are set out, describing their hypoglycemic properties on fasting plasma glucose, post prandial glucose, side-effects, and costs

\section{Properties of currently available blood glucose lowering agents}

\begin{tabular}{|c|c|c|c|c|c|c|c|c|c|}
\hline & AGls & Metformin & SUs & Glinides & TZDs & DPP4i & GLP-1 RA & Insulin & SGLT-2i \\
\hline Effect on fasting glucose* & 0 & +++ & +++ & + & +++ & + & +++ & ++++ & ++ \\
\hline Effect on post prandial glucose ${ }^{*}$ & +++ & + & ++ & +++ & + & +t+ & +t+ & ++++ & ++ \\
\hline Weight"t & 0 & $0 / \downarrow$ & ++ & + & ++ & 0 & $\downarrow$ & +++ & $\downarrow$ \\
\hline Hypoglycemia in monotherapy & 0 & 0 & +++ & ++ & 0 & 0 & 0 & ++++ & 0 \\
\hline CV outcome studiesः & - & + & + & - & + & \multicolumn{2}{|c|}{ on-going } & + & on-going \\
\hline CHD benefit* & + & + & - & - & + & \pm & \pm & \pm & \pm \\
\hline GI side-effects" & + & + & - & - & - & + & + & - & - \\
\hline Other side effects/concerns" & $\begin{array}{l}\text { Episodes of } \\
\text { hypoglycaemia } \\
\text { occurning during } \\
\text { therapy must. } \\
\text { where } \\
\text { appropriate, be } \\
\text { treated by the } \\
\text { administration } \\
\text { of glucose. } \\
\text { not sucrose }\end{array}$ & $\begin{array}{l}\text { Lactic } \\
\text { acidosis. } \\
\text { folate and } \mathrm{B}_{12} \\
\text { absorbtion } \\
\text { decreased }\end{array}$ & $\begin{array}{l}\text { Impaired the } \\
\text { preischemic } \\
\text { precondition } \\
\text { of } \\
\text { myocardium? }\end{array}$ & $\begin{array}{c}\text { Acute } \\
\text { coronary } \\
\text { syndrome. } \\
\text { hyper- } \\
\text { sensitivity }\end{array}$ & $\begin{array}{c}\text { Oedema. } \\
\text { liquid } \\
\text { retention. } \\
\text { CHF. } \\
\text { fractures. } \\
\text { bladder } \\
\text { carcinoma } \\
?\end{array}$ & $\begin{array}{c}\text { Risk of } \\
\text { pancreatitis, } \\
\text { URT } \\
\text { infection }\end{array}$ & $\begin{array}{c}\text { Risk of } \\
\text { pancreatitis }\end{array}$ & $\begin{array}{c}\text { Fluid } \\
\text { retention }\end{array}$ & $\begin{array}{l}\text { UT/GU } \\
\text { infection }\end{array}$ \\
\hline $\operatorname{Cos}^{* * *}$ & ++ & + & + & ++ & ++ & ++ & +++ & variable & $+++? ?$ \\
\hline Experience with the medication" & ++ & ++++ & ++++ & ++ & ++ & + & + & ++++ & - \\
\hline
\end{tabular}

Notes: *Effect: $0=$ neutral; += mild; ++= moderate; +++= moderate to marked; ++++= marked; **effect: $\downarrow=$ favorable; $0=$ neutral; += mild gain; ++= moderate gain; +++= moderate to marked gain; ++++= marked gain; ${ }^{\$}$ Risk: $0=$ neutral; += mild; ++= moderate; +++= moderate to marked; ++++= marked; CV outcome studies, Gl side-effects: $+=$ present, $-=$ not present, \pm not assoc, with CV risk/results of CV outcome trials expected; $* * *$ cost: $+=$ cheap; ++ = quite cheap; +++= expensive; ++++ = very expensive; experience: $+=$ very small; $++=$ small; $+++=$ high; +++ = very high, - new drug. Summary of product characteristics of each drug in the therapeutic class with link to the European Medicines Agency. Copyright (C) 2013 AMD. Reproduced with permission from http://www.aemmedi.it/algoritmi_en_20।3/images/tabella_i.jpg.

Abbreviations: AMD, Associazione Medici Diabetologi (Italy); AGls, alpha-glucosidase inhibitors; SUs, sulphonylureas; TZDs, thiazolidinediones; DPP4i, dipeptidyl peptidase 4 inhibitors; GLP-I RA, glucagon-like peptide-I receptor agonists; CV, cardiovascular; CHD, coronary heart disease; CHF, congestive heart failure; GI, gastrointestinal; URT, upper respiratory tract; UT, urinary tract; GU, genitourinary. 
Table 2 Recommended associations (by the time of review and update of the algorithms in April 20I3) of incretins and SGLT-2i are shown

\section{Permitted combinations with DPP4 inhibitors, GLP-1 receptor agonists, SGIT-2 inhibitors}

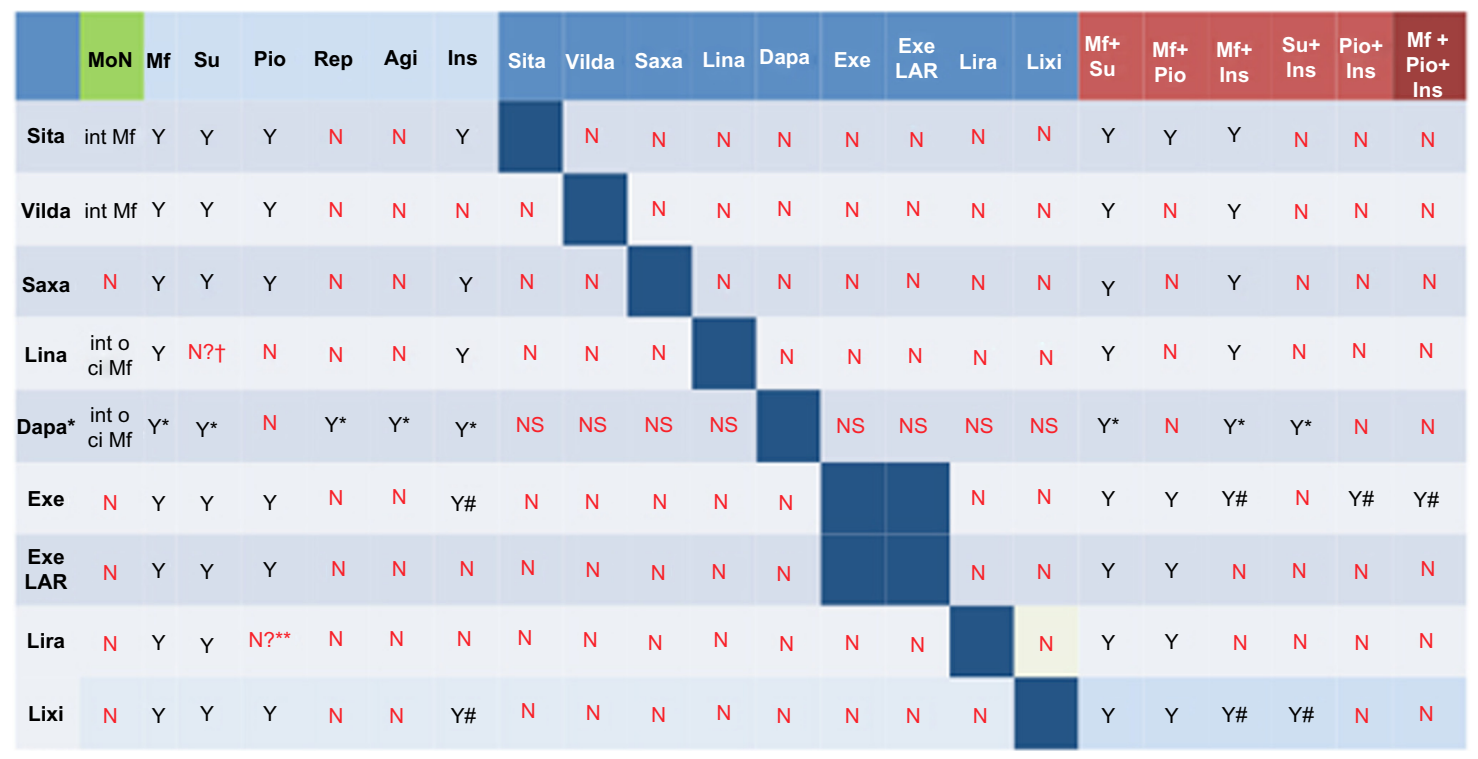

Note: *Prescribed generically in combination with other oral hypoglycemic agents, including insulin. $* *$ But with metformin + pioglitazone $=$ yes. ${ }^{*}$ There are no explicit indications for sulphonylurea alone, but for metformin + sulphonylurea = yes. *Basal insulin alone. Copyright @ 20I3 AMD. Reproduced with permission from http://www. aemmedi.it/algoritmi_en_2013/images/diapo78_algoritmi.jpg.

Abbreviations: AMD, Associazione Medici Diabetologi (Italy); SGLT-2i, sodium-glucose cotransporter type 2 inhibitors; Y, yes; N, no; Mf, metformin; Su, sulphonylurea; Pio, pioglitazone; Rep, repaglinide; Agi, alpha-glucosidase inhibitors (acarbose); Ins, insulin; Sita, sitagliptin; Vilda, vildagliptin; Saxa, Saxagliptin; Lina, linagliptin; Dapa, dapagliflozin; Exe, exenatide; Exe LAR, exenatide long-acting release; Lira, liraglutide; Lixi, lixisenatide; int, intolerance; ci, contraindications; NS, not studied.

- intensive, ie, seven glycemic measurements per day for 3 consecutive days (before and 2 hours after main meals and at bed time).

- staggered, ie, monitoring blood glucose before and 2 hours after breakfast on the first day, before and 2 hours after lunch, and before and 2 hours after the evening meal on the third day; this cycle is repeated until the end of the week.

- self-monitoring of blood glucose five times daily over 3 consecutive days (monitoring blood glucose before breakfast and the evening meal, and 2 hours after the three main meals).

\section{Parameters for the characterization of patients with type 2 diabetes}

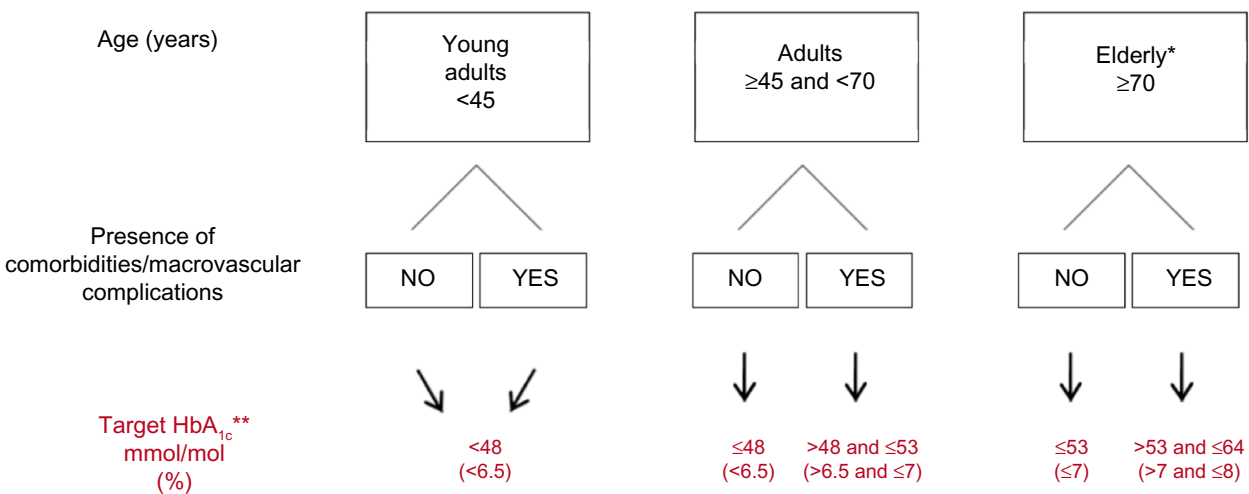

Figure I HbA target has been individualized based on the age of the patient and on the presence of macro-vascular diabetes complications/co-morbidities.

Notes: *Carefully evaluate (at presentation and over the course of time) glomerular filtration rate (GFR), potential hypoglycemia risks (with particular care in the use of sulfonylureas or glinides), nutritional status, and presence of comorbidities/frailty. ${ }^{* *}$ The $\mathrm{HbA}_{\mathrm{lc}}$ target values proposed are intended as safe objectives, limiting the risk of hypoglycemia.

Abbreviation: $\mathrm{HbA}_{1 \mathrm{c}}$, glycated hemoglobin. 
The treating physician in consultation with the patient should establish judiciously both the best scheme of selfmonitoring to be used and the period of time involved (eg, the week preceding the consultation) in order to obtain useful information, taking into account patient convenience and minimization of costs. ${ }^{35}$

Self-monitoring of blood glucose allows two main types of hyperglycemia or patient phenotypes to be recognized, ie, predominantly fasting/preprandial ( $>60 \%$ of fasting/ before-meal values indicating hyperglycemia) and predominantly postprandial ( $>60 \%$ of measurements taken 2 hours after a meal indicating hyperglycemia). The antidiabetic agent (oral or injectable) and insulin are initiated, and then intensified according to the patient phenotype, noting that insulin treatment does not exclude rapid-acting compounds.

\section{Main subcategories seen in clinical practice}

The Italian algorithm takes into account some individual variables and characteristics as follows:

- an initial $\mathrm{HbA}_{1 \mathrm{c}}$ value, ie, a cut-off point of $9 \%$, has been chosen, leading to subcategories and consequently to different therapeutic options

- $\quad$ BMI $<30 \mathrm{~kg} / \mathrm{m}^{2}$ and $\geq 30 \mathrm{~kg} / \mathrm{m}^{2}$

- occupations associated with a risk of hypoglycemia, such as workers at high altitude, pilots, drivers, crane operators, and platform workers

- presence of chronic renal failure

- frail elderly status

According to the main features of the patient, there are six main subcategories (Figure 2). Each flowchart refers to newly diagnosed patients and/or those who are not receiving anti-diabetic treatment. For other cases, the algorithm at the level nearest to the patient's characteristics should be considered. With the exception of the algorithm in Figure 2, which refers to patients with high glucose and $\mathrm{HbA}_{1 \mathrm{c}} \geq 9 \%$, who are treated with lifestyle intervention \pm insulin, these algorithms (Figure 2) also contain separate treatment recommendations for patients who are metformin-intolerant.

\section{Other important considerations}

In all subcategories (Figure 2), treatment starts with lifestyle intervention, ie, diabetes education, physical activity, and medical nutritional therapy. We support the recommendation to intervene on lifestyle first for two reasons, the most obvious one being linked to the importance of education and motivation to modify lifestyle at this stage of the disease, and the other relating to the fact that often, previous nutritional habits may have been so wrong and "absurd" that frank improvement is possible even without drugs. In this situation, after 1-3 months, along with lifestyle interventions, the next therapeutic step includes antidiabetic agents and/or insulin. Insulin treatment may started at any level, even temporarily, according to the judgment of the treating physician, bearing in mind the risk to benefit ratio and costs, eg, weight gain in obese patients and hypoglycemia in frail elderly patients. It is also recommended to step back in the treatment algorithm when necessary.

Target body weight is also individualized in this algorithm. For overweight patients, the aim is to reach and maintain the ideal weight whenever possible. For obese and extremely obese patients, structured lifestyle intervention guided by a multidisciplinary team (diabetologist, dietician, diabetes educator) and a 5\%-10\% decrease in initial body weight (or at least stabilization of weight) are recommended. Bariatric surgery may also considered be for patients with a body mass index $>35 \mathrm{~kg} / \mathrm{m}^{2}$.

Finally, it is worth stressing that the decision process related to each therapeutic level is complex and individualized, and is based on the best knowledge, experience, and judgment of the treating physician, keeping in mind the efficacy of the treatment and patient safety. This algorithm guides the physician through the multiple possible choices of antidiabetic agent (including insulin) or combinations thereof according to the patient's phenotype.
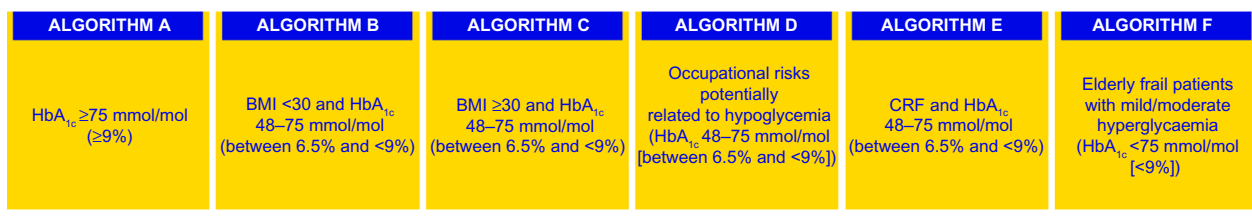

Figure 2 The Italian algorithm.

Notes: The Italian algorithm takes into account some individual variables/main features: initial value of $\mathrm{HbA} / \mathrm{c} ; \mathrm{BMI},<30 \mathrm{~kg} / \mathrm{m}^{2}$ and $\geq 30 \mathrm{~kg} / \mathrm{m}^{2}$; professions associated with hypoglycemia risk such as work at high altitude, pilots, drivers, crane machinists, platform workers, etc; presence of chronic renal failure; frailty of elderly T2D patients. Copyright $\odot 2013$ AMD. Reproduced with permission from http://www.aemmedi.it/algoritmi_en_2013/algoritmi.html.

Abbreviations: AMD, Associazione Medici Diabetologi (Italy); BMI, body mass index; CRF, chronic renal failure; $\mathrm{HbA}_{\mathrm{Ic}}$, glycated hemoglobin. 


\section{Conclusion}

Given that T2D patients are heterogeneous in their clinical features and that T2D is a progressive disease, there is a clinical need for a personalized algorithm that covers these issues. The Italian algorithm for the treatment of T2D is an innovative, accessible, and easy to use dedicated online tool for doctors who treat patients with the disease. It is innovative in that patients can be easily fitted into a clinical category and phenotyped, and the gradual treatment is easy to follow as diabetes progresses. This tool may counteract clinical inertia, and by getting more patients to their fixed targets and reducing long-term complications, may lessen the burden of $\mathrm{T} 2 \mathrm{D}$ and its related costs.

\section{Author contributions}

$\mathrm{AC}$ and $\mathrm{MG}$ wrote the manuscript. RC, ADM, KE, SG, and GM revised, read, and approved the final manuscript. The authors take full responsibility for the content of this paper. AC and MG serve as guarantors. SG contributed to this article on behalf of the AMD and GM on behalf of the Italian Society of General Medicine.

\section{Disclosure}

$\mathrm{AC}, \mathrm{MG}, \mathrm{RC}, \mathrm{ADM}, \mathrm{KE}, \mathrm{SG}$, and GM have received consultancy fees, attended advisory board meetings, or have given lectures for a number of pharmaceutical companies producing antidiabetic drugs.

\section{References}

1. International Diabetes Federation. IDF Diabetes Atlas. 5th ed. Brussels, Belgium: International Diabetes Federation; 2011. Available from: http:// www.idf.org/diabetesatlas. Accessed November 9, 2013.

2. UK Prospective Diabetes Study Group. Overview of 6 years therapy of type 2 diabetes: a progressive disease. Diabetes. 1995;44(11):1249-1258.

3. DeFronzo RA. Banting lecture. From the triumvirate to the ominous octet: a new paradigm for the treatment of type 2 diabetes mellitus. Diabetes. 2009;58(4):773-795.

4. UK Prospective Diabetes Study Group. Intensive blood glucose control with sulphonylureas or insulin compared with conventional treatment and risk of complications in patients with type 2 diabetes (UKPDS 33). Lancet. 1998;352(9178):837-853.

5. Holman RR, Paul SK, Bethel MA, Matthews DR, Neil HA. 10-year follow-up of intensive glucose control in type 2 diabetes. $N$ Engl J Med. 2008;359(15):1577-1589.

6. Tahrani AA, Bailey CJ, Del Prato S, Barnett AH. Management of type 2 diabetes: new and future developments in treatment. Lancet. 2011;378(9786):182-197.

7. Nyenwe EA, Jerkins TW, Umpierrez GE, Kitabchi AE. Management of type 2 diabetes: evolving strategies for the treatment of patients with type 2 diabetes. Metabolism. 2011;60(1):1-23.

8. Inzucchi SE, Bergenstal RM, Buse JB, et al. Management of hyperglycemia in type 2 diabetes: a patient-centered approach. Position Statement of the American Diabetes Association (ADA) and the European Association for the Study of Diabetes (EASD). Diabetologia. 2012;55(6):1577-1596.
9. Turner RC, Cull CA, Frighi V, Holman RR. Glycemic control with diet, sulfonylurea, metformin, or insulin in patients with type 2 diabetes mellitus: progressive requirement for multiple therapies (UKPDS 49). UK Prospective Diabetes Study Group. JAMA. 1999;281(21): 2005-2012.

10. Rodbard HW, Jellinger PS, Davidson JA, et al. AACE/ACE Consensus Statement American Association of Clinical Endocrinologists/ American College of Endocrinology. Consensus Panel on Type 2 Diabetes Mellitus: An Algorithm for Glycemic Control. Endocr Pract. 2009;15(6):540-559.

11. National Institute for Health and Clinical Excellence. Clinical guideline 87 (update of NICE clinical guideline 66). Type 2 diabetes: the management of type 2 diabetes. May 2009. Available from: http://www.nice.org.uk/ nicemedia/live/12165/44322/44322.pdf. Accessed November 9, 2013.

12. Monnier L, Lapinski H, Colette C. Contributions of fasting and postprandial plasma increments to overall diurnal hyperglycaemia of type 2 diabetic patients: variations with increasing levels of HbA1c. Diabetes Care. 2003;26(3):881-885.

13. Qaseem A, Humphrey LL, Sweet DE, Starkey M, Shekelle P; for the Clinical Guidelines Committee of the American College of Physicians. Oral pharmacologic treatment of type 2 diabetes mellitus: a clinical practice guideline from the American College of Physicians. Ann Intern Med. 2012;156(3):218-231.

14. Stone TT, Kivlahan CH, Cox KR. Evaluation of physician preferences for guideline implementation. Am J Med Qual. 1999;14(4):170-177.

15. Khunti K, Davies M. Glycaemic goals in patients with type 2 diabetes: current status, challenges and recent advances. Diabetes Obes Metab. 2010;12(6):474-484.

16. International Diabetes Federation. 2012 Clinical Guidelines Task Force. Global guideline for type 2 diabetes. Available from: http:/www.idf.org/ global-guideline-type-2-diabetes-2012. Accessed November 9, 2013.

17. Virkamäki A, Saltevo J. Finnish Current Care Guideline for Diabetes: interactive approach to improve individualised treatment. Diabetologia. 2011;54(5):1264-1265.

18. Diabetes Treatment Algorithm from the Diabetes Current Care Guideline. Working group set up by the Finnish Medical Society Duodecim and the Finnish Society of Internal Medicine. Available from: http://www.terveysportti.fi/xmedia/ccs/varhainen_diabetes_en.html. Accessed November 9, 2013.

19. Garber AJ, Abrahamson MJ, Barzilay JI, et al; American Association of Clinical Endocrinologists. AACE comprehensive diabetes management algorithm 2013. Endocr Pract. 2013;19(2):327-336.

20. Schernthaner G, Barnett AH, Betteridge DJ, et al. Is the ADA/EASD algorithm for the management of type 2 diabetes (January 2009) based on evidence or opinion? A critical analysis. Diabetologia. 2010;53(7): 1258-1269.

21. Ceriello A, Gallo M, Gentile S, Giorda C, De Micheli A; on behalf of Associazione Medici Diabetologi. To what extent is the new position statement of the American Diabetes Association (ADA) and the European Association for the Study of Diabetes (EASD) 'personalised'? Diabetologia. 2012;55(10):2853-2855.

22. Italian Association of Medical Diabetologists. Personalization of therapy in type 2 diabetes. 2011. Available from: http://www.aemmedi.it/algoritmi_en_2013/intro-english.html. Accessed February 18, 2014.

23. Rodbard D, Vigersky RA. Design of a decision support system to help clinicians manage glycemia in patients with type 2 diabetes mellitus. J Diabetes Sci Technol. 2011;5(2):402-411.

24. Action to Control Cardiovascular Risk in Diabetes Study Group; Gerstein HC, Miller ME, Byington RP, et al. Effects of intensive glucose lowering in type 2 diabetes. $N$ Engl J Med. 2008;358(24):2545-2559.

25. ADVANCE Collaborative Group; Patel A, MacMahon S, Chalmers J, et al. Intensive blood glucose control and vascular outcomes in patients with type 2 diabetes. N Engl J Med. 2008;358(24):2560-2572.

26. Duckworth W, Abraira C, Moritz T, et al; VADT Investigators. Glucose control and vascular complications in veterans with type 2 diabetes. N Engl J Med. 2009;360(2):129-139. 
27. Beigi FI, Moghissi E, Tiktin M, Hirsch IB, Inzucchi SE, Genuth S. Individualizing glycemic targets in type 2 diabetes mellitus: implications of recent clinical trials. Ann Intern Med. 2011;154(8):554-559.

28. Skyler JS, Bergenstal R, Bonow RO, et al. American Diabetes Association; American College of Cardiology Foundation; American Heart Association: Intensive glycemic control and the prevention of cardiovascular events: implications of the ACCORD, ADVANCE, and VA diabetes trials: a position statement of the American Diabetes Association and a scientific statement of the American College of Cardiology Foundation and the American Heart Association. Diabetes Care. 2009;32(1):187-192.

29. Eldor R, Raz I. The individualized target HbA1c: a new method for improving macrovascular risk and glycemia without hypoglycemia and weight gain. Rev Diabet Stud. 2009;6(1):6-12.

30. Rodbard D, Vigersky R. Development of algorithms for clinical decision support for primary care providers. Diabetes Technol Ther. 2005;7(2):409.

31. Vigersky RA, Galen RS, Horne D, Cavotta M, Rodbard D. Computer assisted decision support (CADS) for primary care of diabetes. Telemed E-Health. 2007;13:168.

32. Smith RJ, Nathan DM, Arslanian SA, Groop L, Rizza RA, Rotter JI. Individualizing therapies in type 2 diabetes mellitus based on patient characteristics: what we know and what we need to know. $J$ Clin Endocrinol Metab. 2010;95(4):1566-1574.

33. Del Prato S, LaSalle J, Matthaei S, Bailey CJ; Global Partnership for Effective Diabetes Management. Tailoring treatment to the individual in type 2 diabetes practical guidance from the Global Partnership for Effective Diabetes Management. Int J Clin Pract. 2010;64(3): 295-304.
34. Pozzilli P, Leslie RD, Chan J, et al. The A1C and ABCD of glycaemia management in type 2 diabetes: a physician's personalized approach. Diabetes Metab Res Rev. 2010;26(4):239-244.

35. Ceriello A, Gallo M, Armentano V, Perriello G, Gentile S, De Micheli A; Associazione Medici Diabetologi. Personalizing treatment in type 2 diabetes: a self-monitoring of blood glucose inclusive innovative approach. Diabetes Technol Ther. 2012;14(4):373-378.

36. International Diabetes Federation. 2011 Guideline for management of postmeal glucose in diabetes. Available from: http://www.idf.org/ sites/default/files/postmeal\%20glucose $\% 20$ guidelines.pdf. Accessed November 9, 2013.

37. European Medicines Agency. European public assessment reports. Available from: http://www.ema.europa.eu/ema/index.jsp?curl=pages/ medicines/landing/epar_search.jsp\&mid=WC0b01ac058001d124. Accessed November 9, 2013.

38. Polonsky WH, Fisher L, Schikman CH, et al. Structured, self-monitoring blood glucose significantly reduces A1C levels in poorly controlled, noninsulin-treated type 2 diabetes: results from the Structured Testing Program study. Diabetes Care. 2011;34(2):262-267.

39. International Diabetes Federation. Guideline on self-monitoring of blood glucose in non-insulin treated type 2 diabetes. 2008. Available from: http://www.idf.org/guidelines/self-monitoring. Accessed November 9, 2013.
Pharmacogenomics and Personalized Medicine

\section{Publish your work in this journal}

Pharmacogenomics and Personalized Medicine is an international, peerreviewed, open access journal characterizing the influence of genotype on pharmacology leading to the development of personalized treatment programs and individualized drug selection for improved safety, efficacy and sustainability. This journal is indexed on the American Chemical

\section{Dovepress}

Society's Chemical Abstracts Service (CAS). The manuscript management system is completely online and includes a very quick and fair peer-review system, which is all easy to use. Visit http://www.dovepress. com/testimonials.php to read real quotes from published authors. 